\title{
Seismicity in a Scattered Mining Environment- A Rock Engineering Interpretation
}

\author{
M.J. Dunn AngloGold Ashanti Limited, South Africa
}

The geological complexity of the Witwatersrand Basin in the Klerksdorp area necessitates the use of scattered mining. In 1996, a study was conducted to assess seismic response for different stages and situations in a scattered mining environment. Seven different areas within a geologically complex mining block where analysed in an attempt to assess seismic response in terms of: differences in depth; proximity to geological structures; mining towards solid and mining towards an already mined out area. This analysis was conducted using various statistical and seismicity parameters to describe and compare different mining situations and the rockmass response to production. A rock engineering interpretation of the seismic observations was attempted in terms of anticipated stress levels, deformation and relative seismic hazard. It was possible to explain the seismic observations in practical and logical rock engineering terms and it was found that some parameters were good indicators of the local rockmass stiffness and could be related to areas where high levels of stress induced fracturing were expected. From this it was concluded that seismic observations could assist in day-to-day rock engineering analyses and assist as a decision making tool.

\section{INTRODUCTION}

Great Noligwa Mine (GNM) forms part of the AngloGold Ashanti(AGA) Limited Vaal RiveroperationsnearKlerksdorp. This mine was originally known as Vaal Reefs 8-Shaft. It is situated approximately $170 \mathrm{~km}$ southwest of Johannesburg. The major reef of interest that is exploited is the Vaal Reef within the Main-Bird Series of the Witwatersrand Basin.

The reef is tabular and dips to the southeast at between 10 and 35 degrees. Several large geological structures striking northeast to southwest divide the area into a number of blocks. Throws on geological structures vary from a few metres to hundreds of metres. Due to the complex geology a scattered mining method is applied in this area. This consists of pre-developed strike haulages with crosscuts / raises generally spaced $180 \mathrm{~m}$ apart on strike. Mining at GNM is conducted between 1500 to $2500 \mathrm{~m}$ below surface.

Seismicity in the Klerksdorp area is associated with geological structures. In the early 1970's a regional network was established to monitor mining induced seismicity in the area. This network gradually expanded and in 1994, a decision was made to increase the level of coverage on GNM and several other mines in the area. In January 1996, a ten station seismic network was commissioned to cover the $8 \mathrm{~L}$ block of GNM. The stations consist of triaxial $4.5 \mathrm{hz}$ geophones installed in $8 \mathrm{~m}$ holes drilled into the hangingwall of access tunnels. This mining block was delineated by several large geological structures and had an area of approximately $4 \mathrm{~km}^{2}$. At the time production in this area was approximately $12000 \mathrm{~m}^{2}$ per month.

\section{OVERVIEW OF STUDY}

An initial study was conducted to assess seismicity in this mining environment for the period 19 February to 14 August 1996. During this time, 9908 events were recorded with a minimum of 4 stations. The aims of the study were to investigate rockmass response for different stages in the scattered mining cycle and at different depths and proximity to major geological structures.
Statistical and several other parameters were used in an attempt to describe and compare seismicity for the different areas. The rockmass response was also related to production levels and a rock engineering interpretation of the nature of the seismicity was attempted. An attempt was made to rank the polygons in terms of the seismic hazard.

\subsection{Polygon Description}

Seven different mining situations were identified and a polygon was constructed around each area (Figure 1). The network sensitivity was determined from Gutenberg-Richter plots for each polygon area and was found to be similar as can be seen in Table 1. Each polygon is described below.

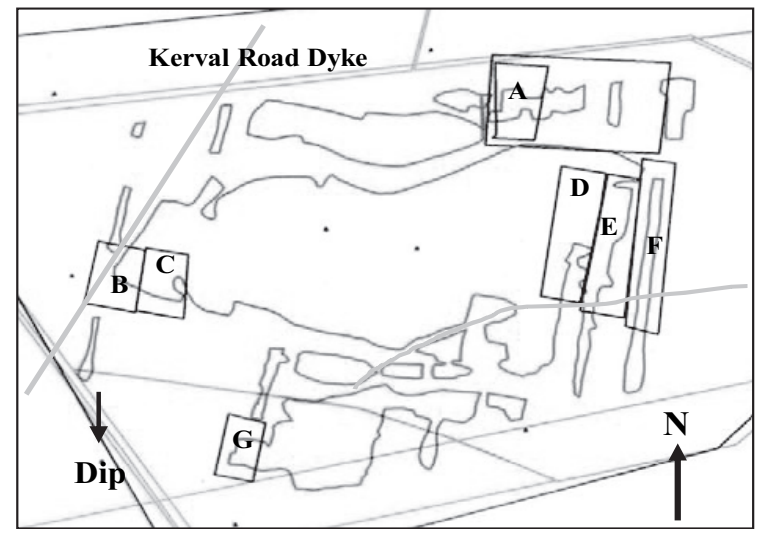

FIG. 1 8L area mining outline and polygons A to $G$

\subsubsection{Polygon A (56 FE 51)}

Mining is being conducted between a large fault and a $50 \mathrm{~m}$ thick dyke. These structures both have normal throws of $200 \mathrm{~m}$ and $30 \mathrm{~m}$ respectively. This polygon is geologically more complex than the others. The average depth is $1618 \mathrm{~m}$ below surface. 
TABLE 1 Sensitivity summary of polygons

\begin{tabular}{ll}
\hline Polygon & $\mathbf{M}_{\min }$ \\
\hline 8L & -0.45 \\
A & -0.30 \\
B & -0.33 \\
C & -0.33 \\
D & -0.28 \\
E & -0.34 \\
F & -0.27 \\
G & -0.15 \\
\hline
\end{tabular}

\subsubsection{Polygon B (61 FW 45 West)}

Mining in this polygon was between a mined area and a dyke. The western mining face of the $61 \mathrm{FW} 45$ raise line is mining towards the intersection of the Kerval Road Dyke and the East-West dyke.

\subsubsection{Polygon C (61 FW 45 East)}

The eastern mining faces of the $61 \mathrm{FW} 45$ raise line are at ninety degrees to the west-east dyke and are mining towards solid ground. The area to the north of the mining faces has been mined out. The average depth is approximately $1823 \mathrm{~m}$ below surface.

\subsubsection{Polygon D (61 FE 53 West)}

Mining in this polygon is being conducted in an underhand configuration towards a mined area. The depth varies between 1700 and $1800 \mathrm{~m}$ below surface. Stress levels and the degree of deformation in this area are expected to be higher than in polygons $\mathrm{E}$ and $\mathrm{F}$.

\subsubsection{Polygon E (61 FE 53 East)}

Mining in this polygon is being conducted in an underhand configuration towards solid ground. The depth varies between 1700 and 1800 ms below surface. The deepest mining panel in this polygon is mining alongside a seismically active dyke.

\subsubsection{Polygon F (61 FE 54)}

This polygon encompasses a raise line where down- dip ledging is being conducted towards the seismically active dyke. Stress levels and the degree of deformation in this polygon are expected to be less than in polygon $\mathrm{D}$. The depth varies between 1700 and $1800 \mathrm{~m}$ below surface.

\subsubsection{Polygon G (68 FW 48)}

Mining in this polygon is being conducted in an overhand configuration towards solid ground. The dip mining span in this area is $70 \mathrm{~m}$ and the average depth below surface is $2000 \mathrm{~m}$. Geologically this polygon is the least complex.

\section{STATISTICAL ANALYSIS}

Several commonly used statistical parameters were used to describe and compare seismicity in the different as well as providing an indication of the relative seismic hazard between the polygons.

\subsection{Seismic Activity Rate}

The seismic activity rate $(\lambda)$ is defined by the following formula:

$$
\lambda=\frac{N}{T}
$$

Where: $\mathrm{N}$ is the total number of events greater than or equal to a certain magnitude and $\mathrm{T}$ is the time span considered. If it assumed that the occurrence of seismic events in time follows a Poisson's distribution, then the approximate standard deviation of $\lambda$ is equal to $\lambda^{1 / 2}$ (Kijko and Funk, 1994).

Table 2 shows the seismic activity rate, standard deviation and mean return time for each polygon for events with local magnitudes greater than 0 and 1 . The time span considered (T) is 177 days.

For seismic events of $M_{L}>0$, polygons $D$ and $F$ had the lowest and highest activity rates respectively, whilst only polygons $B$ and $E$ experienced seismic events with $M_{L}>$ 1. This indicates that polygons $\mathrm{B}$ and $\mathrm{E}$ are more likely to experience a $M_{L}>1$ seismic event.

TABLE 2 Seismic activity rate and mean return period summary

\begin{tabular}{l|ccc|ccc}
\hline Poly & \multicolumn{3}{|c|}{$\mathbf{M}_{\mathrm{L}}>\mathbf{0}$} & \multicolumn{3}{c}{$\mathbf{M}_{\mathrm{L}}>\mathbf{1}$} \\
& $\lambda$ & $\lambda^{1 / 2}$ & $\mathrm{Rp}(\mathrm{m})$ & $\lambda$ & $\lambda^{1 / 2}$ & $\mathrm{Rp}(\mathrm{m})$ \\
\hline 8L & 17.23 & 4.15 & 0.058 & 0.107 & 0.327 & 9.35 \\
$\mathrm{~A}$ & 1.050 & 1.025 & 0.952 & - & - & - \\
$\mathrm{B}$ & 0.746 & 0.863 & 1.340 & 0.034 & 0.184 & 29.50 \\
$\mathrm{C}$ & 0.797 & 0.893 & 1.250 & - & - & - \\
$\mathrm{D}$ & 0.130 & 1.153 & 7.695 & - & - & - \\
$\mathrm{E}$ & 0.983 & 0.980 & 1.017 & 0.028 & 0.014 & 35.71 \\
$\mathrm{~F}$ & 1.328 & 1.152 & 0.753 & - & - & - \\
$\mathrm{G}$ & 0.994 & 0.997 & 1.006 & - & - & - \\
\hline
\end{tabular}

\subsection{Mean Return Period}

The mean return period $[R p(m)]$ between seismic events having a magnitude equal to, or greater than a certain magnitude $(\mathrm{m})$ is given by:

$$
R p(m)=\frac{1}{\lambda(m)}
$$

For seismic events of $M_{L}>0$, polygons $A$ and $F$ have the shortest mean return periods. However, for seismic events of $M_{L}>1$, only polygons $B$ and $E$ have mean return period values with $B$ having the shortest mean return period.

\subsection{Gutenberg-Richter Relation}

The Gutenberg-Richter (G-R) relation is represented by the following equation:

$$
\log N(\geq m)=a-b m
$$

where $\mathrm{N}$ is the number of events of magnitude greater than or equal to a certain magnitude $(\mathrm{m})$ whilst $a$ and $b$ are constants which describe the curve of the G-R relation (Gutenberg and Richter, 1954). The b-value describes the slope of the G-R relation curve or the ratio between small and large events in a given period. A low b-value implies a larger fraction of high magnitude events or increased seismic hazard. Figure 2 shows the G-R relation for the entire 8L area. Note the clearly visible bimodal event population.

\subsection{Maximum Magnitude $\left(M_{\max }\right)$}

The $M_{\text {max }}$ is an indication of the largest magnitude event that can be expected in an area and can be determined in a number of ways. Some of these methods involve complex statistical methods and are described by Kijko and Funk (1994). For this investigation, the expected $\mathrm{M}_{\max }$ was determined from the magnitude of the largest recorded event plus the difference between the largest and second largest seismic event recorded.

This method of determining the expected maximum magnitude is suitable for limited and/or doubtful seismic data. The procedure is quick and easy to carry out. However, 
this method has certain shortcomings. This is demonstrated by polygon $B$ having a higher $M_{\max }$ than the whole $8 \mathrm{~L}$ area as a result of the difference between the largest and second largest event being greater in polygon $\mathrm{B}$. The more complete the data the more reliable would be the $\mathrm{M}_{\max }$ estimate.

The $b$-values and $M_{\max }$ for each polygon are shown in Table 3 . In terms of the $b$-value and $M_{\max }$, polygons $B$ and $E$ have the highest level of seismic hazard associated with them relative to the other polygons. Polygons D and F have a moderate level of seismic hazard associated with them.

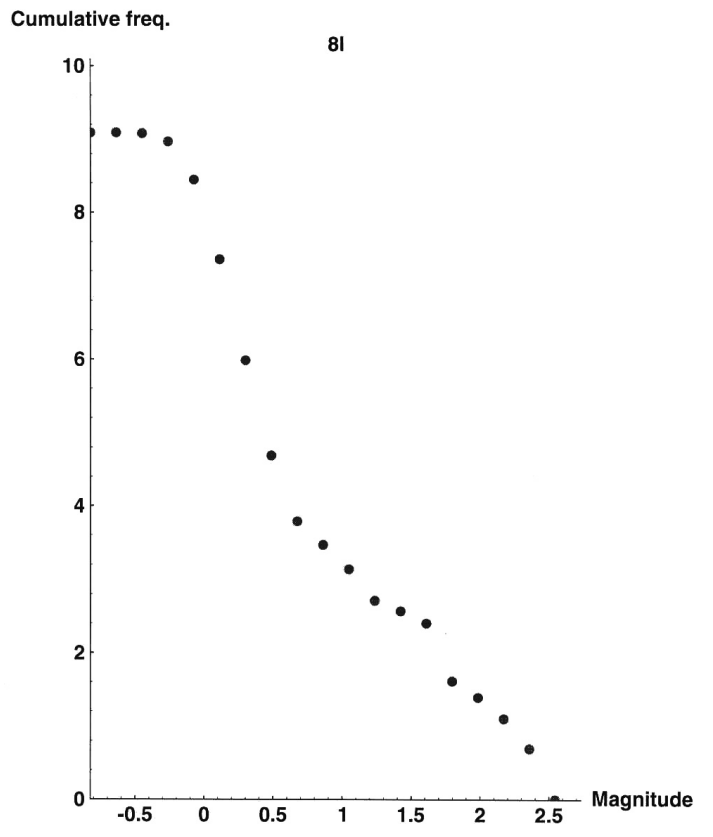

FIG. 2 Gutenberg-Richter plot for the 8L area $(b=1.000)$

\subsection{Probability Analysis}

The probability of a damaging seismic event occurring can be used to determine a relative level of seismic hazard between different areas. Before conducting a seismic hazard assessment, it is necessary to define a damaging seismic event and in the Klerksdorp area, a $M_{L}>2$ event, is regarded as potentially damaging (Kruth, 1998). This does not mean that smaller seismic events cannot cause damage.

Only polygons B and E yielded probability values for seismic events of $M_{L}>2$. The probabilities of having an event of $M_{L}>2$ in the $8 \mathrm{~L}$ area and in polygons $B$ and $E$ are shown in Table 4 for different periods. Polygons $\mathrm{B}$ and $\mathrm{E}$ have a higher risk of occurrence of a damaging seismic event than the other polygons. The probability of having an event of $M_{L}>2$ in these two polygons is considerably less than for the whole $8 \mathrm{~L}$ area.

TABLE 3 Polygon b-value and $M_{\max }$ values

\begin{tabular}{lll}
\hline Polygon & b-value & $\mathbf{M}_{\max }$ \\
\hline $8 \mathrm{~L}$ & 1.103 & 3.45 \\
$\mathrm{~A}$ & 2.202 & 0.64 \\
$\mathrm{~B}$ & 1.320 & 3.58 \\
$\mathrm{C}$ & 1.987 & 0.28 \\
$\mathrm{D}$ & 3.087 & 1.0 \\
$\mathrm{E}$ & 1.307 & 2.3 \\
$\mathrm{~F}$ & 2.223 & 1.2 \\
$\mathrm{G}$ & 2.726 & 0.6 \\
\hline
\end{tabular}

TABLE 4 Probability of having an event of $M_{L}>2$

\begin{tabular}{llll}
\hline Days & 8L Polygon & B Polygon & E Polygon \\
\hline 1 & 0.087458 & 0.001309 & 0.00081 \\
4 & 0.306553 & 0.005228 & 0.004319 \\
7 & 0.473039 & 0.009131 & 0.007547 \\
16 & 0.768741 & 0.020749 & 0.017167 \\
22 & 0.866443 & 0.028418 & 0.023528 \\
31 & 0.941380 & 0.039800 & 0.032992 \\
\hline
\end{tabular}

\subsection{Volume of Ground Motion (VGM)}

According to Mendecki (1985) the VGM is a single number that integrates the probabilities of seismic events occurring at different magnitudes described by the G-R relation and the relation between magnitude, distance, and peak ground velocity. In simple terms, the VGM is an indication of the volume of ground that will be subjected to a certain velocity related to a certain magnitude seismic event and is determined from the following expression:

$$
V G M\left(m_{o}, v\right)=\frac{A v^{c} \lambda T \beta}{B \frac{\exp \left(-B m_{o}\right)-\exp \left(B X_{\max }\right)}{\exp \left(-B m_{\min }\right)-\exp \left(\beta m_{\max }\right)}}
$$

Where:

$m_{o} \quad$ is the minimum magnitude of a seismic event considered important from a damage point of view

$\mathrm{X}_{\max }$ is the maximum observed magnitude during the time interval $\mathrm{T}$

$\mathrm{m}_{\min }$ is the minimum observed magnitude

$\mathrm{m}_{\max }$ is the maximum expected magnitude

$\beta=b^{*} \ln (10)$

$A \quad=4 / 3 \pi \exp \left(-3 a_{3} / a_{2}\right)$

$\mathrm{B} \quad=\beta+3 \mathrm{a}_{1} / \mathrm{a}_{2}$

C $=3 / \mathrm{a}_{2}$

The values for $a_{1}, a_{2}$ and $a_{3}$ are obtained from equation 5 , which relates peak ground velocity $(\mathrm{V}[\mathrm{mm} / \mathrm{s}])$ with event strength (magnitude, Energy [E] or Moment $\left[\mathrm{M}_{\mathrm{o}}\right]$ ) and hypocentral distance $(R[\mathrm{~m}])$.

$$
\log (V)=a_{1} \log (E)+a_{2} \log (R)+a_{3}
$$

For the Klerksdorp area the following general values are used: $\mathrm{a}_{1}=0.469, \mathrm{a}_{2}=-1.363, \mathrm{a}_{3}=1.0019$ (Glazer, 1997).

Generally, this relationship is only valid for determining peak ground velocities in the far field and the relative near field for a given seismic magnitude and distance (Butler and Van Aswegen, 1993). The values for $a_{1} a_{2}$ and $a_{3}$ should differ for different ranges of $\mathrm{E}$ and R. Ground motion equations (6, 7 \& determined by Sciocatti (1996) were used to determine the VGM for each polygon. Only polygons B and E were expected to experience velocities of ground motion related to events with $M_{L}>1$. The VGM expected in these polygons is shown in Table 5.

$$
\begin{aligned}
1700-2000 \mathrm{~m}: & \log (\mathrm{V})=1.12-\log (\mathrm{R})+0.9 \\
1000-1700 \mathrm{~m}: & \log (\mathrm{V})=\mathrm{m}-2 * \log (\mathrm{R})+4.2 \\
660-1000 \mathrm{~m}: & \log (\mathrm{V})=\mathrm{m}-2.8 * \log (\mathrm{R})+6.0
\end{aligned}
$$


TABLE 5 Expected VGM in polygons 8L, B and E

\begin{tabular}{llll}
\hline$M_{L}$ & $\begin{array}{l}\text { VGM }\left(m^{3}\right) \\
\text { Polygon 8L }\end{array}$ & Polygon B & Polygon E \\
\hline 1.0 & 74000 & 1400 & 1700 \\
1.5 & 10000 & 400 & 125 \\
2.0 & 2000 & 100 & 0 \\
2.5 & 0 & 0 & 0 \\
\hline
\end{tabular}

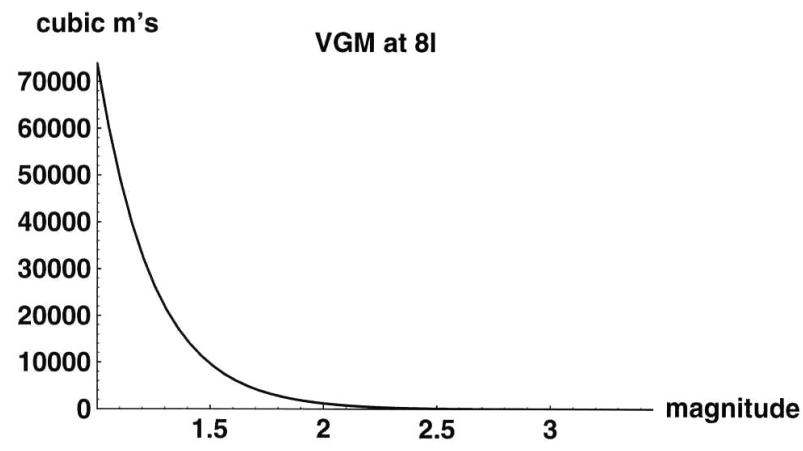

FIG. 3 VGM for the 8 L area (Sciocatti, 1996)

\section{ENERGY-MOMENT (E-M) RELATION}

The E-M relation is defined as follows:

$$
\log (E)=c+d \log (M)
$$

where: $\mathrm{E}$ is the energy, $\mathrm{M}$ is the moment, whilst $\mathrm{c}$ and $\mathrm{d}$ are constants describing a best-fit line through the data.

The best-fit line describes the ratio of radiated seismic energy to seismic moment. Mendecki (1993) showed that this ratio is consistently higher for events occurring at greater depth and within a more competent and less faulted rockmass.

The E-M plots for each polygon show that generally the ratio of radiated seismic energy to seismic moment increases with depth. Figure 4 shows the E-M plot for the 8L area. It appears as if there may be more than one population of seismic events. This phenomenon is seen to a lesser or greater extent in all of polygons as can be seen in polygons B and C (Figures 5 and 6).

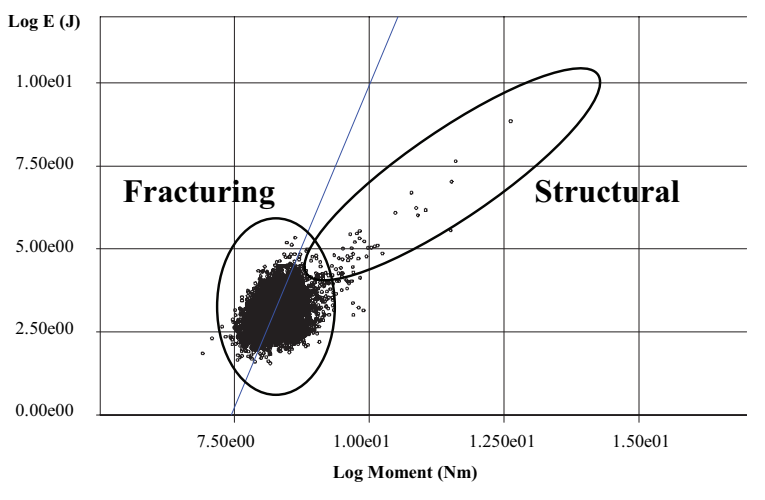

FIG. 4 E-M relation for the 8L area $(d=3.876 ; c=-28.832)$

The E-M relation A and $\mathrm{B}$ values for each polygon are summarized in Table 6. A high d-value and a low c-value indicate a steeper gradient, meaning that a higher amount of seismic energy is radiated for a certain seismic moment. The slope of the E-M relation can be used to indicate the relative stiffness of the rockmass.
TABLE 6 Energy-Moment relation values

\begin{tabular}{lll}
\hline Polygon & d-value & c-value \\
\hline 8L & 3.876 & -28.832 \\
A & 1.960 & -13.438 \\
B & 3.430 & -25.340 \\
C & 1.270 & -7.590 \\
D & 2.210 & -15.440 \\
E & 2.130 & -14.410 \\
F & 2.890 & -20.390 \\
G & 3.850 & -28.420 \\
\hline
\end{tabular}

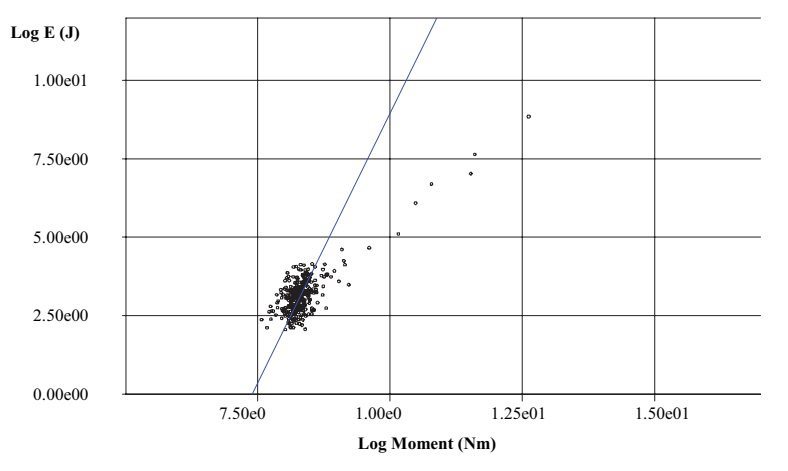

FIG. 5 E-M relation for polygon B $(d=3.340 ; c=-25.338)$

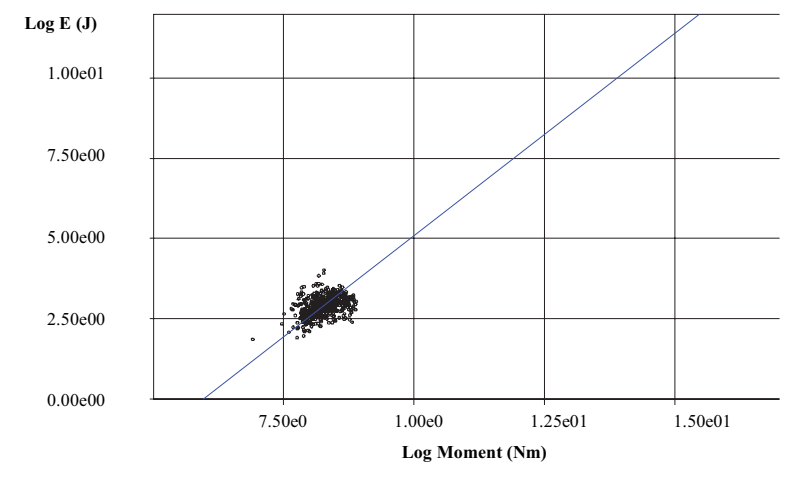

FIG. 6 E-M relation for polygon $C(d=1.262 ; c=-7.528)$

The best-fit line for polygon $\mathrm{C}$ is considerably flatter than that of polygon B. By filtering out the events of $M_{L}<-0.2$ in polygon $\mathrm{C}$, an E-M relation similar to that for polygon $\mathrm{B}$ was obtained (Table 7).

TABLE 7 E-M relation values for polygons $B$ and C

\begin{tabular}{lllll}
\hline $\mathbf{M}_{\mathbf{L}}$ range & \multicolumn{2}{l}{ Polygon B } & \multicolumn{2}{l}{ Polygon C } \\
& d & C & d & C \\
\hline-0.9 to -0.2 & - & - & 5.161 & -38.677 \\
-0.9 to 0.5 & 5.446 & -41.995 & 1.262 & -7.528 \\
-0.9 to 4.0 & 3.430 & -25.338 & 1.270 & -7.592 \\
\hline
\end{tabular}

The filtering out of events $M_{L}>0.5$ resulted in polygon $B$ having a steeper E-M relation than polygon $C$. This indicates that possibly the rockmass is stiffer in polygon B than in polygon C. This is logical since in polygon B mining is occurring towards solid, whilst in polygon $\mathrm{C}$, mining is being conducted along an abutment where the rockmass would be fractured and less stiff. 


\section{ENERGY INDEX (EI)}

Energy index is an indicator of a variation in state of stress. The energy index of a seismic event is the ratio of the radiated seismic energy ( $\mathrm{E}$ ) of that event to the average radiated energy for events of the same seismic moment ( $\mathrm{M}_{\mathrm{o}}$ ) (Van Aswegen and Butler, 1993).

$$
E I=\frac{E}{\bar{E}\left(M_{o}\right)}
$$

EI is sensitive to the E-M relation on which it is based. If a single E-M relation were used, the deeper parts would generally show higher values of energy index than shallower areas. Table 8 shows the variation in average EI using different E-M relations. Generally, EI increase with increasing depth as expected when using a single general E-M relation. The first $\mathrm{E}-\mathrm{M}$ relation used is for the 8L area, the second E-M relation is a general relation for the Klerksdorp area.

When using an E-M relation for each polygon the average EI index does not necessarily increase with depth. When using the general E-M relation for the Klerksdorp area, an anomalously high value of average EI is obtained for polygon C. This indicates that the rockmass is highly stressed in this area relative to the other areas. However, the apparent stress values for this polygon indicate that the area is less highly stressed than polygon B. Lower values of average EI are obtained using the other two E-M relations. These values are similar and indicate that polygon $C$ is less stressed than polygon $\mathrm{B}$, which correlates with the apparent stress values obtained.

TABLE 8 Average El for different E-M relations

\begin{tabular}{llll}
\hline Polygon & $\begin{array}{l}\mathbf{8 L} \\
\mathbf{d}=\mathbf{3 . 8 7 6} \\
\mathbf{c}=\mathbf{- 2 8 . 8 3 2}\end{array}$ & $\begin{array}{l}\text { Regional } \\
\mathbf{d = 1 . 8 0 7} \\
\mathbf{c}=\mathbf{- 1 1 . 9 3 3}\end{array}$ & $\begin{array}{l}\text { Polygon as per } \\
\text { Table 6. }\end{array}$ \\
\hline $\mathrm{A}$ & 0.75 & 1.10 & 1.36 \\
$\mathrm{~B}$ & 1.87 & 2.59 & 3.15 \\
$\mathrm{C}$ & 1.52 & 21.27 & 1.48 \\
$\mathrm{D}$ & 0.82 & 1.94 & 2.14 \\
$\mathrm{E}$ & 2.24 & 4.0 & 1.58 \\
$\mathrm{~F}$ & 2.93 & 7.42 & 1.74 \\
$\mathrm{G}$ & 3.44 & 11.56 & 7.10 \\
\hline
\end{tabular}

Figure 7 is an EI plot of an area encompassing polygons D, $E$ and F. Higher EI values are observed when mining towards solid ground and when mining near geological structures.

\section{APPARENT STRESS}

Apparent stress $\left(\sigma_{A}\right)$ is recognised as a model independent measure of the dynamic stress release (Madariaga, 1976; Snoke et al., 1983; Boatwright, 1984) and is determined by the following relationship:

$$
\sigma_{A}=G \times \frac{E}{M_{o}} \quad \text { (where } \mathrm{G} \text { is rigidity) }
$$

Consistently higher (or lower) values of apparent stress associated with seismic events of similar moments in an area of interest would indicate higher (or lower) level of stress and/or rock strength. Big variations in apparent stress associated with seismic events of similar moments in a given area would be an indication of inhomogeneous stress and/or rock strength (Mendecki, 1993).

Figure 8 shows the variation of apparent stress for events of a similar seismic moment in the $8 \mathrm{~L}$ area. Generally the apparent stress increases with depth. The ratio of the largest to smallest apparent stress is approximately 50 . In polygon

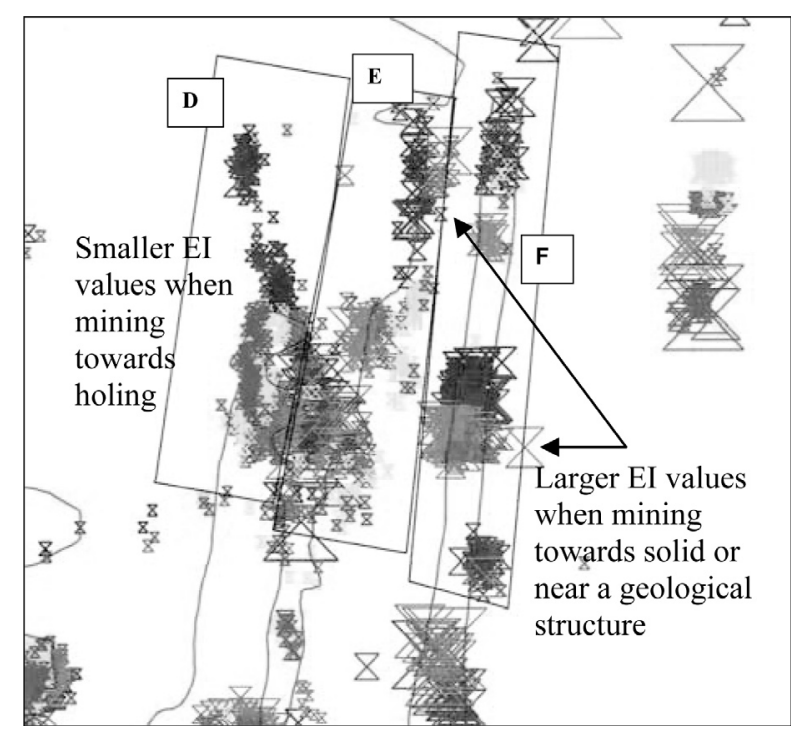

FIG. 7 Energy index values for polygons $D, E$ and $F$. Note the higher values when mining towards solid and a geological structure

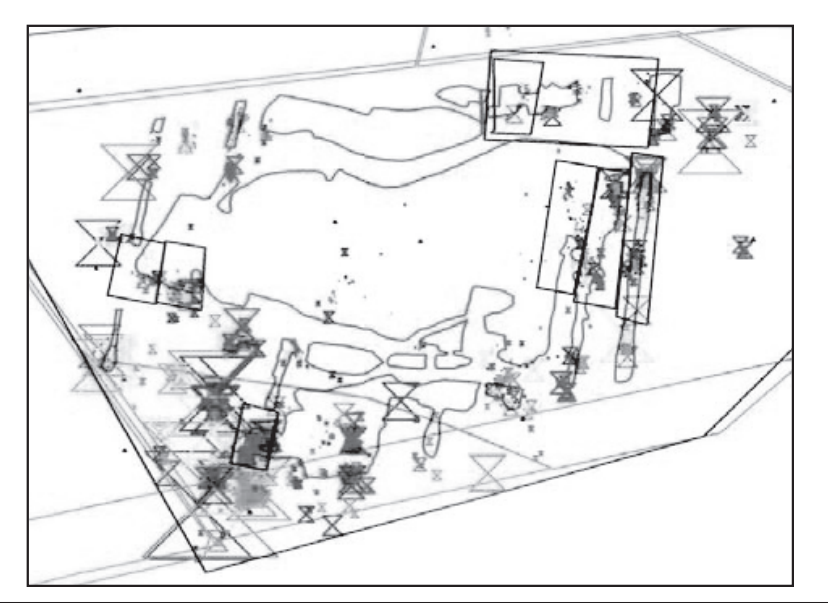

FIG. 8 Apparent stress values in the $8 \mathrm{~L}$ area

A it can be seen that the apparent stress values are lower. Higher values of apparent stress are observed in the area east of polygon A where mining towards solid ground or next to solid ground was being conducted.

For an area that encompasses polygons D, E and F (Figure 9) the ratio of the highest apparent stress to lowest apparent stress in this area is approximately 30 . Lower values of apparent stress are seen in polygon $\mathrm{D}$ where the mining faces approach holing. Higher values of apparent stress are seen in polygons $\mathrm{E}$ and $\mathrm{F}$.

Higher apparent stresses are seen in polygon B. This may be due to the higher stresses associated with the Kerval Road Dyke. Evidence of this was observed in the form of high closure rates in the ledging area west of the dyke. Lower apparent stress values in $C$ may be related to the abutment and fault along which the mining faces are stripping. The fault and the abutment represent a softer rockmass.

High values of apparent stress are observed in polygon G. Lower apparent stresses are observed directly ahead of the face with the apparent stress values increasing with distance ahead of the face. These lower apparent stresses are associated with a weaker rockmass ahead of the face that is 
highly fractured. The competency of the rockmass should increase with distance ahead of the face resulting in higher values of apparent stress.

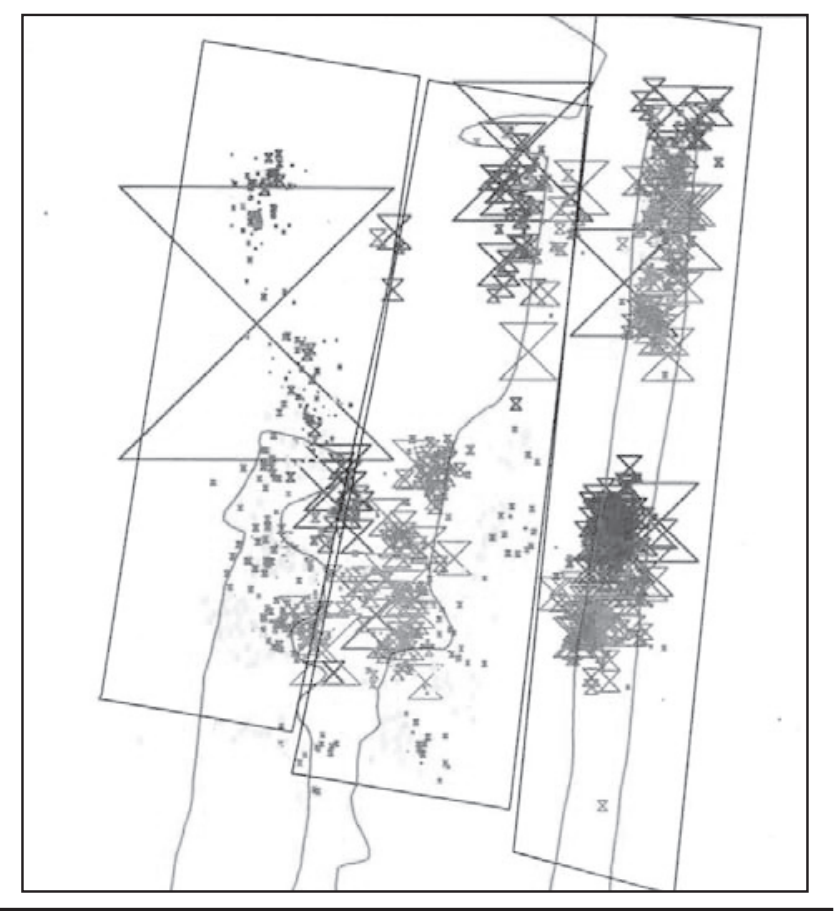

FIG. 9 Apparent stress values for polygons D, E and F

\section{APPARENT VOLUME ( $\left.\mathbf{V}_{A}\right)$}

Mendecki (1993) defines $V_{A}$ as follows:

$$
V_{A}=\frac{M}{2 \sigma_{A}}=\frac{M^{2}}{2 G E}
$$

The apparent volume for a given seismic event scales volume of rock with coseismic inelastic strain of an order of apparent stress over rigidity. It has a scalar nature and can be easily manipulated in the form of cumulative or contour plots which can be used to gain insight into the rate and distribution of coseismic deformation and / or stress transfer in the rockmass.

Generally, it is accepted that a significant increase in the rate of coseismic inelastic deformation increases the potential for a larger seismic event. In polygon $\mathrm{A}$, there was a significant increase in the cumulative $\mathrm{V}_{\mathrm{A}}$ during July as production increased.

In polygon $\mathrm{B}$ a high cumulative $\mathrm{V}_{\mathrm{A}}$ was observed recorded during May, mostly due to two large events, A rapid increase in cumulative $\mathrm{V}_{\mathrm{A}}$ was observed in July and can be related to a seismic event of $M_{L}=2.9$.

In polygon $\mathrm{D}$ there was an increase in the average apparent volume during July as a number of panel faces approached holing into a mined area (Figure 10).

An increase in the rate of coseismic deformation was observed in polygon E during August as mining of a panel next to a dyke commenced. Generally, higher apparent volumes are observed next to this structure.

In polygon $\mathrm{F}$ an increase in the rate of coseismic inelastic deformation was observed in July corresponding with two down dip ledging faces approaching a dyke.

Generally it can be seen that the rate of coseismic inelastic deformation increases as mining faces approach holing and when mining near geological structures.

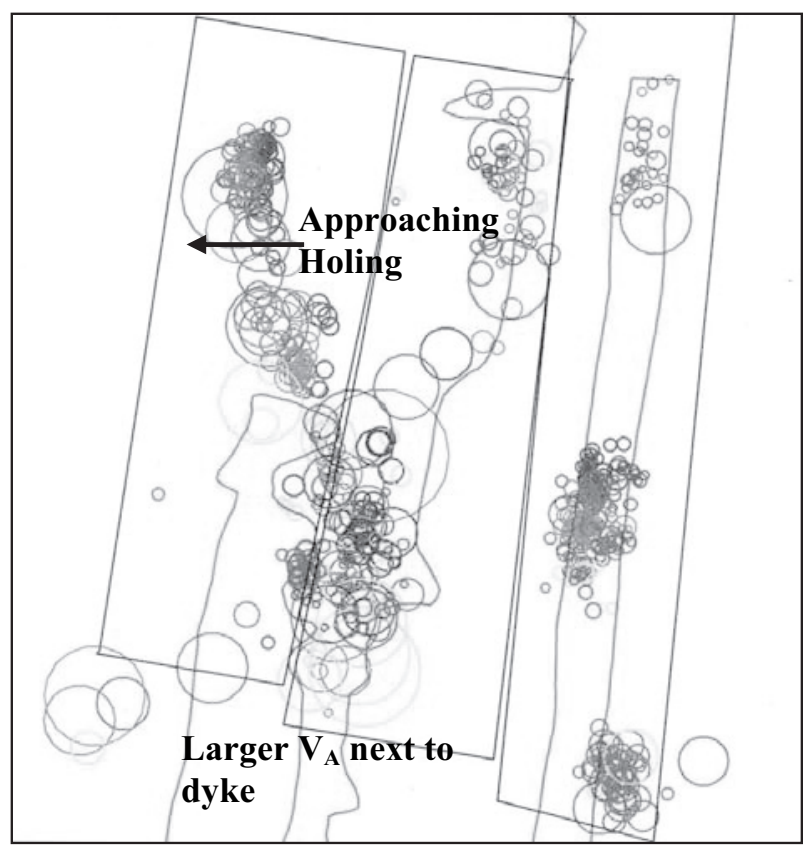

FIG. 10 Apparent volumes in polygons D, E and F

\section{COMPARISON OF SEISMICITY}

Seismicity can be described by the following four independent parameters:

- average time between events

- average distance between connective events

- sum of seismic energies $(\Sigma \mathrm{E})$

- sum of seismic moments $(\Sigma \mathrm{M})$

A number of parameters describing seismicity can be calculated from these parameters for a given volume (Mendecki, 1997).

A number of the polygons were compared using some seismicity parameters. Two analyses were conducted. The first was to determine if there was any difference in seismicity with increasing depth with polygons A, B, C and G being used (Table 9). The second was to determine the differences in seismicity for different mining scenarios with polygons $\mathrm{D}, \mathrm{E}$ and $\mathrm{F}$ being included in the analysis (Table 10). The sensitivity and volumes considered in each analysis were comparable.

\subsection{Seismic Stress}

The seismic stress measures stress changes due to seismicity and is determined by the following expression.

$$
\sigma_{S}=\frac{2 G \sum E}{\sum M}
$$

The seismic stress values for polygons A, B, C, and G are shown in Table 9. An analysis was conducted to determine if differences in seismic stress between the polygons were significant. There seem to be significant difference between polygon $\mathrm{A}$ and the other polygons. The most significant difference was between the shallower and deeper polygons especially between polygons $\mathrm{A}$ and $\mathrm{G}$ and between polygons $\mathrm{C}$ and $\mathrm{G}$.

For polygons D, E and $\mathrm{F}$ the same analysis was conducted (Table 10). Again the differences in seismic stress were significant whilst the most strongly significant difference was between polygons $\mathrm{D}$ and $\mathrm{F}$. 


\subsection{Seismic Strain Rate}

Seismic strain rate $\left(\xi_{s}\right)$ is an indication of the rate of coseismic inelastic deformation and is determined from the following expression (Mendecki, 1997).

$$
\xi_{S}=\frac{\sum M}{2 \mu V t}
$$

From Table 9 it can be seen that the rate of coseismic inelastic deformation for polygon $B$ is higher than for polygons $A$, $\mathrm{C}$ and $\mathrm{G}$. For polygons D, E and F (Table 10) it can be seen that the rate of coseismic inelastic deformation is higher in polygons $\mathrm{E}$ and $\mathrm{F}$ than in polygon $\mathrm{D}$. In both comparisons the higher rate of coseismic deformation is related to mining in the vicinity of geological structures.

\subsection{Seismic Viscosity}

Seismic viscosity $\left(\eta_{\mathrm{s}}\right)$ describes the flow of seismic inelastic deformation. A lower seismic viscosity implies easier flows of seismic inelastic deformation or easier stress transfer due to seismicity and is determined from the following expression (Mendecki, 1997):

$$
\eta_{S}=\frac{\sigma_{S}}{\xi_{S}}
$$

When evaluating the values of seismic viscosity to determine if there where significant differences between the polygons, similar results as for the seismic stress analysis were obtained.

\begin{tabular}{|c|c|c|c|c|}
\hline Polygon & A & B & C & $\mathbf{G}$ \\
\hline Area $\left(m^{2}\right)$ & $3.00 e+04$ & $3.00 e+04$ & $3.00 e+04$ & $2.00 e+04$ \\
\hline Volume $\left(\mathrm{m}^{3}\right)$ & $2.63 e+06$ & $2.52 \mathrm{e}+06$ & $2.55 e+06$ & $1.85 e+06$ \\
\hline Average Depth (m) & 1618 & 1828 & 1818 & 1983 \\
\hline Cum. $\operatorname{AV}\left(m^{3}\right)$ & $7.20 e+05$ & $1.00 e+06$ & $7.53 e+05$ & $3.54 \mathrm{e}+05$ \\
\hline Number of Events & 322 & 340 & 478 & 480 \\
\hline Cum. M (Nm) & $7.40 e+10$ & $5.10 e+12$ & $1.10 \mathrm{e}+11$ & $9.70 e+10$ \\
\hline Cum. Energy (J) & $2.20 e+05$ & $7.70 e+08$ & $5.10 e+05$ & $1.10 e+06$ \\
\hline Seismic Stress(Bars) & 1.8 & 90.0 & 2.8 & 7.1 \\
\hline Seismic Stress Std. Dev. (Bars) & 0.1 & 61.1 & 0.2 & 0.5 \\
\hline Seismic Strain & $4.717 e-04$ & $3.398 e-02$ & $7.165 \mathrm{e}-04$ & $8.690 e-04$ \\
\hline Seismic Strain Rate (/s) & $3.2 \mathrm{e}-14$ & $2.4 \mathrm{e}-12$ & $5.246 e-14$ & $6.608 e-14$ \\
\hline Seismic Viscosity(Pa.s) & $5.556 e+18$ & $3.710 e+18$ & $5.321 e+18$ & $1.080 e+19$ \\
\hline Seismic Viscosity Std. Dev.(Pa. s) & $3.961 e+17$ & $2.867 e+18$ & $4.250 e+17$ & $1.010 e+18$ \\
\hline Average Apparent Stress & 1.1 & 3.4 & 1.8 & 4.3 \\
\hline Median Apparent Stress & 0.9 & 2.1 & 1.3 & 3.55 \\
\hline Average El & 1 & 2.36 & 14.63 & 9.44 \\
\hline
\end{tabular}

TABLE 9 Comparison of seismicity parameters for polygons A, B, C and G

\begin{tabular}{|c|c|c|c|}
\hline Polygon & D & $\mathbf{E}$ & $\mathbf{F}$ \\
\hline Area $\left(m^{2}\right)$ & $5.00 e+04$ & $5.00 e+04$ & $5.00 e+04$ \\
\hline Volume $\left(\mathrm{m}^{3}\right)$ & $1.32 \mathrm{e}+07$ & $1.24 \mathrm{e}+07$ & $9.61 e+06$ \\
\hline Average Depth (m) & 1728 & 1708 & 1728 \\
\hline Number of Events & 479 & 433 & 777 \\
\hline Cum. Moment (Nm) & $9.30 e+10$ & $1.80 e+11$ & $1.33+11$ \\
\hline Cum. Energy (J) & $3.00 e+05$ & $3.10 e+06$ & $1.50 e+06$ \\
\hline Cum. $A V\left(m^{3}\right)$ & $9.26 e+05$ & $8.05 e+05$ & $4.13 e+05$ \\
\hline Seismic Stress (Bars) & 1.9 & 10.6 & 6.6 \\
\hline Seismic Stress Std. Dev. (Bars) & 0.2 & 3.1 & 0.5 \\
\hline Seismic Strain & $1.183 e-04$ & $2.356 \mathrm{e}-04$ & $2.324 \mathrm{e}-04$ \\
\hline Seismic Strain Rate (/s) & $7.777 \mathrm{e}-15$ & $1.549 \mathrm{e}-14$ & $1.573 e-14$ \\
\hline Seismic Viscosity(Pa. s) & $2.490 e+19$ & $6.829 e+19$ & $4.192 e+19$ \\
\hline Seismic Viscosity Std. Dev. & $2.848 e+18$ & $2.041 e+19$ & $3.242 e+18$ \\
\hline Average Apparent Stress & 1.0 & 3.6 & 3.6 \\
\hline Median Apparent Stress & 0.8 & 2.5 & 2.6 \\
\hline Average El & 1.71 & 3.59 & 6.50 \\
\hline
\end{tabular}

TABLE 10 Comparison of seismicity parameters for polygons D, E and F 


\section{SEISMICITY AND PRODUCTION}

An analysis was carried out to determine if any general relationship exists between the rate of production and seismicity. The cumulative moment for each polygon was plotted against the square metres mined per month (Figure 11). For the 8L polygon it can be seen that there is a change in gradient of the cumulative seismic moment curve related to production. An increase in production generally results in an increase in the gradient of the cumulative moment curve. This was generally observed in all polygons although in some cases there appeared to be time lag between the production rate and change in gradient of cumulative moment. Possibly the six months duration of this study was insufficient.

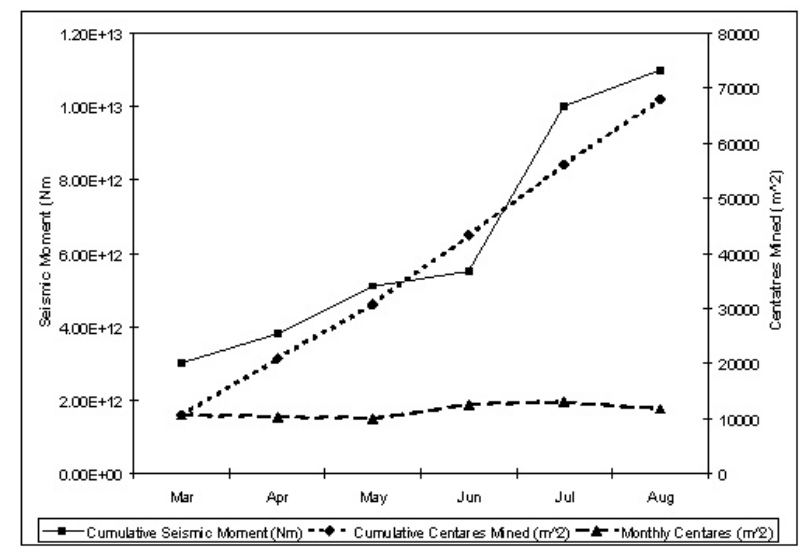

FIG. 11 Cumulative seismic moment versus production for the 8L area

\section{DISCUSSION}

\subsection{Statistical Analysis}

Seismic activity rate can be a useful tool as it includes all events. If the network sensitivity remains constant, the activity rate can be used to identify anomalous behaviour in the rockmass. The high activity rate in polygon $\mathrm{F}$ is probably due to the close proximity to the dyke and the manner in which the dyke was approached. Mean return period is useful to determine the time period between events of a certain magnitude.

The G-R b-value is a useful indication of seismic hazard. However, for a number of the polygons it appears as if there may be more than one b-value. This is as a result of a bimodal event population, involving two different processes (Ebrahim-Trollope et al., 1999; Ebrahim-Trollope, 2001). This is also clearly seen in the E-M relation plots.

The b-value determined for each polygon is a combination of the two b-values and therefore is not a true indication of the seismic hazard in the different areas. Ideally, the two event populations should be separated to determine the true b-value for an area. This can be achieved using various filters, however, there is always a level of uncertainty as to whether the correct data has been filtered out. If it is assumed that the presence of two seismic event populations is normal and consistent for all areas, then using the b-values comparatively may be a more reasonable approach to assign a relative seismic hazard.

The expected $M_{\max }$ can be used to compare the seismic hazard between different areas. Variations in $M_{\max }$ with time can be used to qualitatively determine the level of seismic hazard for particular mining strategies. $M_{\max }$ is used to determine the VGM for an area of interest. This is a useful indicator of what volume will be subject to a ground velocity sufficient to cause damage and could be a possible input into support design.

Using these statistical seismic hazard parameters, an attempt was made to determine the relative level of seismic hazard for the different polygons. This was done by using a value between 1 and 7 and ranking each parameter. A low value indicates a low level of seismic hazard. These rankings were summed to give an overall ranking (Table 11).

Polygons B and E have the highest level of seismic hazard associated with them. In both cases mining is being conducted in the vicinity of dykes that are known to be problematic.

An important factor that must be considered when conducting a statistical hazard analysis is the time period considered. By including all data, the complete history of an area is analysed. This approach is useful for determining the potential of an area or specific geological structure to yield large seismic events. The shortcoming of this approach is that seismic events that do not influence the present situation are included in the data. Other aspects to be considered are mining concentrations, volume and distribution in space.

TABLE 11 Statistical hazard analysis ranking

\begin{tabular}{llllllll}
\hline Polygon & A & B & C & D & E & F & G \\
\hline Activity Rate & 2 & 3 & 5 & 6 & 4 & 7 & 6 \\
Rp. $(\mathrm{m}>1)$ & 0 & 7 & 0 & 6 & 0 & 0 & 0 \\
b & 4 & 6 & 5 & 1 & 7 & 3 & 2 \\
$\mathrm{M}_{\max }$ & 3 & 7 & 2 & 4 & 6 & 5 & 2 \\
VGM $\left(\mathrm{M}_{\mathrm{L}}>1\right)$ & 0 & 6 & 0 & 0 & 7 & 0 & 0 \\
Total & 9 & 29 & 12 & 17 & 24 & 15 & 10 \\
Rank & 1 & 7 & 3 & 5 & 6 & 4 & 2 \\
\hline
\end{tabular}

\subsection{Energy-Moment Relation and Energy Index}

The phenomena of what appears to be a bimodal event population in the $8 \mathrm{~L}$ area has been observed across the Vaal Reefs area. One explanation for this is that a number of different seismic processes may be taking place. Seismic events related to the actual fracturing of the rock would have a higher ratio of radiated seismic energy to seismic moment whereas events associated with movement along geological discontinuities have a lower ratio of radiated seismic energy to moment (Ebrahim-Trollope et al., 1999; Ebrahim-Trollope, 2001).

The lower ratio of radiated seismic energy to moment seen in polygon $\mathrm{C}$ could be because mining is stripping along a fault and an abutment. The rockmass has a lower stiffness in this area due to fracturing and geological weaknesses. In polygon B mining took place towards an intersection of two geological structures and solid ground. This could explain why polygon $\mathrm{B}$ has a strong bimodal distribution, whilst polygon $\mathrm{C}$ does not show this characteristic.

\subsection{Apparent Stress}

The trends observed in the $8 \mathrm{~L}$ area correlate well with what is stated in the literature. Higher apparent stress values are observed in areas of expected high stress with lower values being observed in areas where the rockmass is fractured such as when holing is approached. Lower apparent stress values were also observed related to some geological structures.

Seismic events associated with a less competent rockmass or weak geological discontinuities would have larger seismic moments for given radiated seismic energies compared with events associated with a more competent rockmass or 
hard geological discontinuities, which are considered stiffer. An increase in seismic moment will result in a decrease in apparent stress for the same radiated seismic energy.

\subsection{Apparent Volume}

For a certain radiated seismic energy, events associated with a weak rockmass or a geological discontinuities will have larger seismic moments for the same radiated energy. A larger seismic moment will result in the event having a higher apparent volume. This is seen in polygon $\mathrm{D}$ where the apparent volume increases as mining approaches holing.

Initially in scattered mining, the ground between two raises is solid with a fracture zone of a few metres ahead of the faces. Events associated with this stiffer rockmass would have lower apparent volumes as observed. As mining progresses and the pillar between the two mining face becomes smaller and eventually reaches a stage where it is completely fractured. This softer rockmass is characterised by larger apparent volumes. This could be used as a useful indicator of possible ground control problems that could be expected. As holing is approached, worse conditions are anticipated due to the highly fractured rockmass.

Higher values of apparent volume are also observed in polygon $\mathrm{E}$ when mining commenced next to a dyke. In polygon $\mathrm{F}$ there was an increase in the apparent volumes for events as the dyke was approached. This can be explained by the fact that geological weakness could have a larger seismic moment for a similar radiated energy. Different structures could have different strengths or stiffnesses, resulting in differences in seismic moment and hence apparent volume. Possibly this could be used to characterise the nature of particular structures.

\subsection{Production Rate and Seismicity}

The comparison of cumulative seismic moment with production indicates that seismicity tends to track production. However, this is not constant and sometimes the relationship is direct with an increase in production rate resulting in an almost immediate increase in seismicity. In other cases, there appears to be a time lag in the response of seismicity to changes in production rate. This trend has been observed in other areas on Vaal Reefs (Ebrahim-Trollope et al., 1999).

\subsection{Seismic Hazard Using Seismicity Parameters}

The higher values of seismic stress, average and median apparent stress and average energy index indicate that polygons B and $G$ have a higher level of seismic hazard than polygons $\mathrm{A}$ and $\mathrm{C}$. Polygons $\mathrm{E}$ and $\mathrm{F}$ have higher values of seismic stress, average and median apparent stress and average energy index than polygon $\mathrm{D}$ indicating a lower level of seismic hazard in polygon D.

The rating system used in Table 11 was used to rate the seismicity parameters for the different polygons relative to each other. The results shown in Table 12 indicate that polygons B, E, F and G have the highest level of seismic risk. The rankings allocated to each polygon for seismic stress correlates well with the results of the statistical hazard analysis.

\subsection{Combined Seismic Hazard Rating}

By adding the total rankings for the statistical seismic hazard analysis and the seismicity parameters hazard analysis it is possible to determine a combined relative seismic hazard ranking. This combined seismic hazard ranking includes probability of occurrence, expected ground motions and spatial distribution of the seismic hazard associated with mining in a certain area. The results of the combined seismic hazard analysis indicate that polygons $\mathrm{B}$ and $\mathrm{E}$ have the highest level of relative seismic hazard, whilst polygons A and D have the lowest. This corresponds well, with what was intuitively expected from reviewing the mining configurations in the polygons relative to geological structures.

TABLE 12 Seismic hazard using seismicity parameters

\begin{tabular}{llllllll}
\hline Polygon & A & B & C & D & E & F & G \\
\hline Seismic Stress & 1 & 7 & 3 & 2 & 6 & 5 & 4 \\
Ave App. Stress & 1 & 4 & 3 & 2 & 5 & 5 & 7 \\
Median App. & 2 & 4 & 3 & 1 & 5 & 6 & 7 \\
Stress & & & & & & & \\
Av. El & 1 & 4 & 3 & 2 & 5 & 6 & 7 \\
Total & 5 & 19 & 12 & 7 & 21 & 22 & 25 \\
Rank & 1 & 4 & 3 & 2 & 5 & 6 & 7 \\
\hline
\end{tabular}

TABLE 13 Combined seismic hazard analysis

\begin{tabular}{llllllll}
\hline Polygon & A & B & C & D & E & F & G \\
\hline $\begin{array}{l}\text { Statistical } \\
\text { parameters }\end{array}$ & 9 & 29 & 12 & 17 & 24 & 15 & 10 \\
$\begin{array}{l}\text { Seismicity } \\
\text { parameters }\end{array}$ & 5 & 19 & 12 & 7 & 21 & 22 & 25 \\
Combined & 14 & 48 & 24 & 24 & 45 & 37 & 35 \\
Ranking & 1 & 7 & 2 & 2 & 5 & 4 & 3 \\
Relative Hazard & L & H & L & L & H & M & M \\
\hline
\end{tabular}

\section{CONCLUSIONS}

The occurrence of two different seismic processes with one being related to fracturing of the rockmass and the other with movement along pre-existing geological weaknesses explains the observed bimodal distribution. Amidzic (2001) indicated that bimodal distributions observed in the West Wits area where as a result of development blasts in follow behind tunnels. This explanation would not be valid in the $8 \mathrm{~L}$ area, as scattered mining using pre-developed tunnels is used.

The E-M relation and the G-R relation determined from bimodal event distributions could be misleading when calculating parameters such as energy index or when conducting seismic hazard analyses.

Generally, the statistical seismic hazard assessment yielded reasonable results that where in line with the author's expectations, based on several years knowledge of mining within the area. If statistical methods are used quantitatively to rank different areas, it appears that the assumption that the bimodal distribution is present in all areas and can be considered constant is valid. This needs to be investigated further.

Using seismicity parameters to rank the polygons yielded slightly different results, although in four areas the results were very similar. When the rankings were combined and an overall ranking determined it was in line with expectations. In general terms, this study indicated that seismic hazard increased both with proximity to geological structures and increasing depth.

Energy index and apparent stress were useful indicators of the relative stress between polygons, as well as differences in rockmass stiffness. These parameters provided a more realistic interpretation when compared to the commonly used elastic numerical codes that do not take rockmass fracturing into account. 
Apparent volume was a useful indicator of the rockmass stiffness and was useful in explaining rockmass deformation and behaviour when mining towards holing or adjacent to an abutment.

Overall the various statistical and seismological parameters applied in the study were useful in showing the relative differences between the polygons for different mining scenarios. This approach can be applied by rock engineers to characterise areas and improve their understanding of the rockmass behaviour.

\section{ACKNOWLEDGMENTS}

The author would like to thank the management of AngloGold Ashanti Limited for permission to publish this paper and ISSI personnel who assisted in the original project especially Gerrie Van Aswegen.

\section{REFERENCES}

Amidzic, D. (2001) Energy-moment relation and its application. In Proceedings of RASIM 5 - Dynamic Rockmass Response to Mining, 17-20 September (eds. G. Van Aswegen, R.J. Durrheim, W.D. Ortlepp) SAIMM. Johannesburg. pp. 509-513.

Boatwright, J. (1984) Seismic estimates of stress release. J. Geophys. Res. 89: pp. 6961-6968.

Butler, A.G. and Van Aswegen, G. (1993) Ground velocity relationships based on a large sample of underground measurements in two South African Mining areas. In Proceedings of the 3rd International Symposium on Rockbursts and Seismicity in Mines, Kingston, Canada (ed. R.P. Young) Balkema, Rotterdam, pp. 41-50.

Ebrahim-Trollope, R., Glazer, S.N., Stankiewicz, T. and Kijko, A. (1999) Seismological analyses for a scattered mining environment - methods and their limitations. In Proceedings of SARES 99 - 2nd Southern African Rock Engineering Symposium (ed. T.O. Hagan) Johannesburg, pp. 141-146.

Ebrahim-Trollope, R. (2001) Gutenberg-Richter relationship and mine induced seismicity as observed at African Rainbow Minerals mines - Klerksdorp. In Proceedings of RASIM 5 - Dynamic Rockmass Response to Mining, 17-20 September (eds. G. Van Aswegen, R.J. Durrheim and W.D. Ortlepp) SAIMM. Johannesburg. pp. 501-509.

Glazer, S.N. (1997) Practical applications of stress index and other seismological parameters in combating rockburst hazard in deep gold mines of Vaal Reefs, South Africa. Unpublished PhD Thesis.

Gutenberg, B., and Richter, C.F., (1954) Seismicity of the earth and associated phenomena. 2nd Edition. Princeton University Press.

Kijko, A. and Funk, C.W. (1994) The assessment of seismic hazard in mines. J.S. Afr. Inst. Min. Metall. pp. 179-185.

Kruth, Y. (1998). Damage potential as a result of a large seismic event. Internal report, AngloGold.

Madariaga, R. (1976) Dynamics of an expanding circular fault. Bull. Seism. Soc. Am. 66: pp. 639-666.

Mendecki, A.J. (1985) An attempt to estimate seismic hazard in the AAC gold mine areas. Internal Report, AAC Research and Development services.

Mendecki, A.J. (1993) Real time quantitative seismology in mines. In Proceedings of the 3rd International Syposium on Rockbursts and Seismicity in Mines, Kingston, Canada, (ed. R.P. Young) Balkema, Rottterdam, pp. 287-296.

Mendecki, A.J. (1997) Quantitative Seismology and Rockmass Stability. In Seismic Monitoring in Mines (ed. A.J. Mendecki) Chapman \& Hall, London, pp. 178-219.

Sciocatti, M. (1996) Pers. Comm.

Snoke, T.A., Linde, A.T. and Sacks, I.S. (1983) Apparent stress: An estimate of stress drop. Bull. Seism. Soc. Am. 73: pp. 339-348.

Van Aswegen, G. and Butler, A.G. (1993) Application of quantitative seismology in South African gold mines. In Proceedings of the 3rd International Symposium on Rockbursts and Seismicity in Mines, Kingston, Canada (ed. R.P. Young) Balkema, Rotterdam, pp. 261-266. 